\title{
AGRICULTURAL INFORMATION SHARING FOR CLIMATIC RISK ADAPTATION BY SMALLHOLDER LIVESTOCK FARMERS IN EASTERN AMHARA REGION, ETHIOPIA
}

\author{
aHabtemariam Assefa, aPaul Kibwika, aFlorence B. Kyazze, billion Getinet \\ a Department of Extension and Innovation Studies, Makerere University, Kampala, Uganda. \\ ${ }^{b}$ International Livestock Research Institute, Addis Ababa, Ethiopia.
}

ARTICLE INFO

\section{Article History}

Received: February 13, 2021

Revised: April 15, 2021

Accepted: August 25, 2021

\section{Keywords}

Information sources

Pathway

Climatic risk

Diffusion

North Wollo
A B S T R A C T

This study aims at appraising the needed agricultural information, sources and the pathways that livestock farmers used for climatic risk adaptation in Eastern Amhara Region and also, determining factors that influenced farmer's decision in selecting information pathways. Cross-section survey research design was used for the study. Sample was selected using multistage sampling design. From three agroecological zones, three districts and nine PAs were covered by the study. In the household survey, 317 livestock farmers were interviewed for quantitate data collection. Furthermore, FGD and Key Informant interviews were conducted to supplement survey's result. Data were analysed using STATA (version 14) software. Descriptive and inferential statistical analysis were deployed. The study revealed that livestock farmers needed different agricultural information to adapt climatic risks. The prominent information was relating to feed quality improvement, feed preservation, animal health management and soil and water conservations. Most farmers obtained the information from relatives, extension workers and fellow farmers. Informal discussion, farm-visit, training and village-meetings were the pathways that livestock farmers used to acquire agricultural information. The decision of a farmer in selecting information pathways was determined by different factors, but they differ from pathway to pathways. For example, radio selection was influenced by livestock size the farmer owned and extension access, while train was influenced by membership of farmer groups and credit access. In conclusion, livestock farmers need a diverse agricultural information to adapt climatic risks. They acquire the information from their intimate sources through affordable information pathways. To be effective in climatic risk adaptation, information provision should be need based, delivered through multisource and pathways. Besides, the existing conventional information pathways should also be supported by ICT resources and demonstration. Considering the determinate factors of information pathway selection is very crucial in designing information diffusion strategy.

Corresponding Author: Habtemariam Assefa

Email: assefahabtemariam@yahoo.com

(C) The Author(s) 2021.

\section{INTRODUCTION}

Agriculture information is an indispensable factor in building a strong and self-sufficient economy for any nation through sustainable agriculture development
(Gebru et al., 2017; Mbanda-Obura et al., 2017; Adio et al., 2016). It raises farmers' awareness to adopt agricultural innovations, reduces uncertainty and improve the quality of decision making in solving 
agricultural problems, achieving food security and improving livelihood (Mwalukasa, 2013; Lwoga et al., 2011). By providing relevant information, farmers can be capacitated to assess possible risks in their surroundings and use improved technologies to tackle them(Nyasimi et al., 2016; Mittal and Mehar, 2015). In this regard, many efforts have been done in knowledge generation and diffusion to develop agriculture in Ethiopia. Agriculture, particularly livestock, plays significant roles in providing job opportunity, improving food security and reducing poverty in rural part of the country. Livestock farmers in Ethiopia face new challenges to deal with climate change related risks. Changing rainfall patterns and temperatures altered livestock production system and adversely impacted livestock farmers. Massive animal death, draught power reduction, unintended animal selling and incurring extra cost of feed and healthcare were the common adverse impacts of the risks in Eastern Amhara Region (Assefa et al., 2020). Limited supply and use of agricultural information on livestock innovation were one of the stumbling factors among others. Thus, accessing information on climate change and adaptation strategies can enhance farmers adaptive capacity to climatic risks (Mbanda-Obura et al., 2017). This needs to intensify agricultural information dissemination using the existing information sources and pathways.

Farmers in developing countries, including Ethiopia, access agricultural information from various sources with multiple information pathways (Mbanda-Obura et al., 2017; Mittal and Mehar, 2015). Livestock farmers in Eastern Amhara Region also use various agricultural information to manage climatic risks and boost their livestock production. Despite of this, livestock farmers in the area still remain vulnerable to negative impacts of climatic risks. Hence, it is important to better understand the nature and relevance of information that livestock farmers are getting from the sources and types of information pathways they use. It is also important to understand factors that determined farmer's decision in selecting information pathways in order to enhance the efficiency of information diffusion process in managing climatic risk (Gebru et al., 2017; Beliyu, 2018).

Previous studies in Ethiopia shown that farmers received different agricultural information from different sources using various information pathways. For example, farmers sourced information on improved agricultural technologies from their neighbor in southern Ethiopia (Tewodros and Tesfaye, 2018), extension workers, family members and farmer groups in Tigray region (Gebru et al., 2017) and Agricultural and Rural development office and own experience in Western Amhara region (Habtemariam et al., 2015). Other studies tried to address type of agricultural knowledge and sources that the extension personnel used (Beliyu, 2018). They sourced the information from higher agricultural officers, mass media and newspapers through training, extension meetings, radio, field visit and manual (Borko, 2014). In other African countries like Kenya, farmers used various modern (i.e. mass media and extension services) and traditional (i.e. interpersonal or face-to-face) pathways to receive information on improved technologies (Muriuki et al., 2016). Though these studies are valuable, they are often crop biased and others are generic. There is still much needed to be known about livestock farmers' information needs, sources and pathways used for adapting to climatic risks. The studies are also limited in their insight of determinant factors of the farmers in using a particular information pathway. Therefore, this study sought to address two interrelated research question, namely 1) what are the information needs, the sources and the pathways that livestock farmers in Eastern Amhara region of Ethiopia use for adapting climatic risks? 2) what are the factors that influence livestock farmers' decision in using a specific information pathway in Eastern Amhara region, Ethiopia.

\section{Theoretical framework}

This study anchored to innovation diffusion theory (Rogers, 1995). The theory tried to explain how, why and at what rate new information/ technology spread in certain society. In this theory, diffusion of innovation is defined as the process of communicating an innovation through certain channels over time among the members of a social system. Thus, it has four main elements such as innovation, communication channels/pathways, time and social system. The current study mainly focused on the three elements of diffusion theory to see the needed information, the sources and the pathways that livestock farmers used to adapt climatic risks. To solve agricultural problems, smallholder farmers share agricultural information from different sources (Muriuki et al., 2016; Rees et al., 2000) through various information pathways (Assefa et al., 2011). 
Information sharing is meaningful exchange of ideas, facts and opinions between two or more people to bring significant behavioural change(Hilary et al., 2017; Kamarudin et al., 2015). It involves both sharing of information by the source; and acquiring and applying of information by the recipient (Mtega and Ngoepe, 2018) Information is the facts or message of something such as an innovation, an organization, service or an event that provided from the sources to receivers (David and Cofini, 2017). The source of information refers to institutions or individuals provide message or expertise to the recipients (Mbanda-Obura et al., 2017). While, information pathway refers to the channels or methods or vehicles through which information is shared among the member of social system. It can be horizontal (i.e., peer-to-peer through face-to-face interactions, word of mouth, farmer meetings) and vertical (i.e., upwards and downwards amongst farmers, extension providers and researcher to farmers, use of radios, cell phone) pathways (Nyasimi et al., 2016).
In innovation diffusion, information is generated, improved and shared between individuals (Masrom et al., 2018). Thus, using appropriate information pathway is more crucial for effective communication and innovation diffusion. So, livestock farmers should use appropriate communication pathways to be effective in understanding and applying new agricultural information in process of climatic risk adaptation. Due to different determinant factors, however, all farmers do not have equal access to all information pathways. As the result, they may use different pathways for similar or different information.

This study conceptualizes that livestock farmers may use different agricultural information for different adaptation strategies. They may obtain the information from various sources through different information pathways. Framers' choice of information pathway may also be influenced by various factors, such as demographic, socioeconomic, institutional and agroecology. The theory is farmed pictorially as bellow.

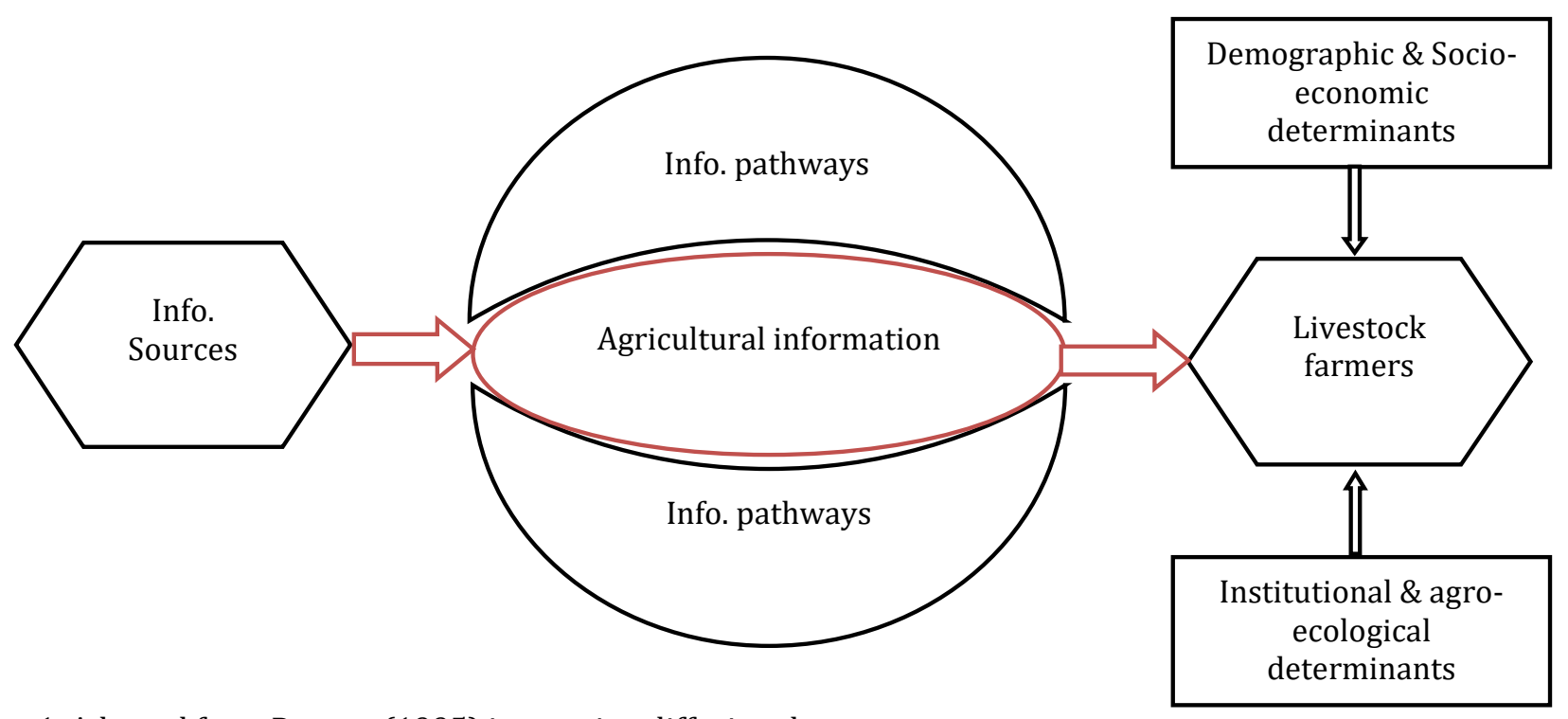

Figure 1. Adapted from Rogers, (1995) innovation diffusion theory.

\section{METHODOLOGY}

\section{Research design and sampling}

A cross-sectional survey research design was used to study the information need, their sources and pathways in climatic risk adaption. Household survey, FGD, key informant interview and personal observation were deployed to collect information for the study. A multistage sampling technique was used to select representative respondents. From Eastern Amhara region, North Wollo zone was selected purposely because of its highly experienced with recurrent climatic risks, potential in livestock production and divers agroecologic zones. The zone was further clustered into three agro-ecologies, namely highland, midland and lowland zones. Then, one district was randomly selected from each agro-ecology zone to capture the variation that 
attributed to agro-ecological difference. From each district, three Peasant Associations (i.e., the lowest administrative unit) were selected randomly. Finally, households were selected randomly from the sampling frame. Sample size was determined using the formula of Chand et al. (2012). In total, 317 livestock farmers were interviewed for household survey.

$\mathrm{n}=\frac{\mathrm{NP}(1-p) x^{2}}{N \cdot e+x P(1-p)}$

Where $\mathrm{n}=$ is the sample size, $\mathrm{N}=$ is the population size, $x$ $=$ Confidence level at $95 \%, \mathrm{Z}=1.96, \mathrm{P}=(\mathrm{P}(1-\mathrm{p}))$ $=$ Estimated population proportion $(0.5), \mathrm{e}=$ is the precision level at $5 \%(0.05)$.

Three FGDs, one from each agro-ecology zone, were carried out. Each FGD comprised 10 participants from different social groups - elders, youth and women. And also 23 key informants were interviewed from different profession and organizations.

\section{Type of data, sources and collection}

Both quantitative and qualitative data were collected. Quantitative data were collected using household survey from livestock farmers. Pretested semi-structure questionnaire was used for the survey. Whereas, qualitative data were collected using Focus Group Discussions (FGDs). The sessions were moderated using checklist in collaboration with PA's development agent. Furthermore, Key Informant (KI) interviews were also conducted to collect additional qualitative information from knowledgeable and experienced individuals in livestock production, climatic risk impacts and adaptation measures in the study zone. They were elders, community leaders, development agents; and experts from Livestock Development Agency, Safety Net program, Disaster and Risk Prevention program at district, zone and region levels and also, from NGOs (i.e., Organization for Rehabilitation in Amhara (ORDA), Den Sectors, Save the Children and World vision) and researchers from Srinka Agricultural Research Center and Woldia University. In both qualitative data collection, consent voice recording was used to assist the data collection. In addition, farmers' field observations were also made as part of the qualitative information appraisal procedure.

\section{Data analysis}

Both descriptive and inferential statistics were used to analyse the data collected from household survey, while thematic analysis was used for qualitative responses from FGDs and KI interviews. The analysis was begun by describing the characteristics of livestock producers. Descriptive analysis was also used to describe the information needs, their sources and pathways. Inferential statistic like Multivariate probit mode was used to analyse the determinant factors of the farmer in selecting a particular information pathway.

\section{Empirical specification of the model-Multivariate Probit Model}

Smallholder farmers in Ethiopia used different pathways to acquire different or same agricultural information for their needs. The variable pathway was used as dummy variable with yes/no response. To estimate the relationship for such kind of variable, non-linear regression model is important (Greene, 2002). In this regard, empirical specification for selection decision over the five groups of information pathways is framed in two possible models i.e., multinomial probit model or multivariate probit model.

One of the bases for using multinomial models is that the outcome variables are independent or the error terms of the selected equations are mutually exclusive (Greene, 2002). In practice, however, the choices among information pathways are not mutually exclusive. Due to the diverse impacts of climatic risks, farmers in the study area use different communication pathways simultaneously to acquire information they need for their adaptation. This implies that the error terms of each information pathways equations may correlated. Thus, using multinomial probit model could ignores the error terms correlation of information pathway selected equations. This may result in bias and inefficient estimation in determining the factors that influence information pathways selection decision.

On the other hand, multivariate probit model considers the possible coexisting correlation in the use of different information pathways simultaneously. The model takes account the correlation in the error terms by jointly modelling the effects of a set of covariates on each of dependent variables and estimates a set of binary probit models' disturbances (Mittal and Mehar, 2013; Donkoh et al., 2019). Regarding this, different studies (Jairo and Korir, 2019; Takele et al., 2019; Yirga et al., 2015) shared that using multivariate probit mode increases the efficiency of modelling interdependency technologies selection decision. Thus, multivariate probit model was selected for this study to determine factors that 
influences farmers' decision to use a particular information pathway by considering simultaneous decision making in pathways selection. Empirically the model is specified as below:

$Y_{i j}^{\prime}=\beta_{i j} X_{i j}+\varepsilon_{i j}$

Where, $Y_{i j}^{\prime}$ is a latent variable which captures the observed and unobserved preferences associated with the $\mathrm{j}^{\text {th }}$ information pathway for household i, $X$ is vectors of covariate that affects the selection decision of the farmer (i.e., demographic, socioeconomic, institution and location characteristics), $\beta$ is vector of unknown parameters to be estimated $(\mathrm{j}=1,2 \ldots 5)$ and $\varepsilon$ is stochastic error term. Out of ten possible information pathways, five of them were selected using principal component analysis. These are radio, training, village-meeting, study tour and demonstration/ field days. The binary dependent variable of the model is specified as below:

$Y_{i j}=1$, if $Y_{i j}^{\prime}>0$ and 0 otherwise

Where, $Y_{i j}$ is the binary of $\mathrm{j}^{\text {th }}$ information pathways used by the $i^{\text {th }}$ household $(i=1,2, \ldots \& 317)$.

Since the farmer had wide variations selection pattern across different combinations of information pathways, there is a possibility of correlation between the selected information pathways. To test this hypothesis, pair-wise correlation coefficients and maximum likelihood ration test was used from the residuals of multivariate probit model. The correlation coefficient can be positive or negative. If the coefficient is positive, the selected information pathways is complemented by the other associated pathway (i.e. complementarity association); whereas if it is negative, selected information pathway is substituted by the associated pathways (i.e. substitute association) (Oladimeji et al., 2020). The estimated regression coefficient of the model cannot show the magnitude of the marginal effects of the covariates on the expected value of the dependent variable; rather it shows the likelihood of the dependent variables' occurrence (Murage et al., 2012; Cornelißen and Sonderhof, 2008). Hence, the study needs to quantify the partial effect of each covariate over information pathways selection decision. The marginal effects were calculated from each independent probit model of pathway selection equation. Marginal effects tell us how the outcome variable change when an explanatory variable change. Following Gc and Yeo (2019), the marginal effects were calculated by the following equation:

$\frac{\Delta y i}{\Delta x i}=\beta i, i=1,2,3, \ldots \ldots, n$

Where, $y i$ is the likelihood of event $\mathrm{i}$ which increase the selection of information pathway option and $\beta i$ is the standard univariate normal density distribution function.

Before running the model, multiclonality was tested using Variance Inflation Factors (VIF). According to Shrestha (2020), VIF measures how much the variance of the estimated regression coefficient is inflated if the independent variables are correlated. VIF is calculated as:

$\mathrm{VIF}=\frac{1}{1-R^{2}}$

Where, the value of VIF is $1<\mathrm{VIF}<5$; the variables are moderately correlated to each other. The small values of VIF corresponding to the variables show that there is no collinearity problem in the model. If value of VIF $>10$, the regression coefficients are feebly estimated with the presence of multicollinearity.

\section{RESULT AND DISCUSSION}

\section{Social-economic characteristics of livestock farmers}

Socio-economic characteristic of the sampled livestock farmers is illustrated in Table 1. Livestock farmers in North Wollo Zone were dominated by male headed household (77.6\%). Most of them were married with average of $45.56 \pm 10.88$ years old. This was relatively higher than the age reported in Afar region, which was 39 years old (Philimon et al., 2016). Majority of the famers did not attend formal education. It was acknowledged that this finding had relatively lower educated farmers than that of the national percentage, i.e. $44.2 \%$ (Central Statistical Agency, 2013) but higher than reported in Southern Afar region, i.e. 28.8\% (Mekuyie et al., 2018). This attributed to nomadic lifestyle and relatively less expansion of education in Afar region.

On average, the farmers had $5.2 \pm 1.6$ family size, of which $2.6 \pm 1.5$ members were educated. This family size was similar with the national average family size, i.e. 5.1 
(Central Statistical Agency, 2013) and lower than what reported from Southern Afar Region, which accounts for 7.9 (Mekuyie et al., 2018). In addition to crop-livestock farming, most of the farmers involved in none-farm activities to support their family. They had on average $22.9 \pm 11.0$ years of experience in livestock farming and operated their livestock farming with the size of $2.9 \pm 1.8$
TLU and $0.8 \pm 0.5$ ha of farmland. Most of the farmers also involved in different farmer-groups and had access to livestock extension, which is good opportunity to the farmers to get new agricultural information. However, most of them did not have access to credit services to finance their livestock farming.

Table 1. Socio-demographic characteristic of livestock farmers in North Wollo zone.

\begin{tabular}{lcc}
\hline Variables & Frequency & Percentage \\
\hline Sex & & \\
Female & 71 & 22.40 \\
Male & 246 & 77.60 \\
\hline Merital status & 39 & 12.30 \\
Married & 278 & 87.70 \\
\hline Educational status & & 59.9 \\
Non-educated & 190 & 40.1 \\
\hline Had noted & 127 & 79.18 \\
\hline Had farmer-group membership & 251 & 64.2 \\
\hline Had extension access & 203 & 84.5 \\
\hline Had credit access & 268 & 43.9 \\
\hline Age & 139 & $\mathrm{SD}$ \\
\hline Family size & Mean & 10.9 \\
\hline Number of educated family members & 45.6 & 1.6 \\
\hline Livestock size (TLU) & 5.2 & 1.5 \\
\hline Land size in hectare & 2.6 & 1.8 \\
\hline Year of experience in livestock production & 2.9 & 0.5 \\
\hline Note: where SD is the stantivities & 0.8 & 11.0 \\
\hline
\end{tabular}

Note: where SD is the standard deviation

\section{Agricultural information needs and their sources}

Livestock farmers in Norh Wollo Zone experienced with various climatic risks, namely drought, animal disease outbreak, frost and flood. As indicated in Table 2, the farmers needed a diverse agricultural information from various sources for their climatic risk adaption. Information on feed preservation and quality improvement $(85.5 \%)$ was the major needed information by livestock farmers. This attributed to using crop residues as major feed resources in the study area. This crop residue, however, is poor in nutrition with high fiber and low protein contents; and also less palatable to animals (Tiruneh and Tegene, 2018). In addition, the availability of feed resource was not uniform throughout the year. In harvesting seasons (i.e., November to January), farmers obtained surplus feed from green pasture and crop residues. In other season (i.e., March to Jun), feed became scant for most livestock farmers. As the result, farmers needed to know more about different mechanisms to preserve surplus feed and improve crop residue utilization.

Moreover, animal healthcare related information (78.5\%) was also needed to adapt the adverse impacts of animal disease outbreaks. In this regard, farmers gave prior to prevention strategies, like vaccination, deworming and spraying. This urged the farmers to know more about the season of a particular animal disease eruption, its prevention strategy and time of provision. Information on soil and water conservation strategies (73.2\%) was also other important needed information because water shortage and poor soil fertility were the serious problem of the study area and made livestock sector highly vulnerable to various climatic risks. Due to this, farmers were more interested in constructing different soil and water conservation structures, promoting area closure and tree plantation. 
Even though meteorological information plays significant role in climate change adaptation, it seems less important for livestock farmers in the study area. It was because farmers in the study area did not use the information regularly and intentionally for their agricultural decision making. According to FGD' participants, the terminologies and details of broadcasting weather information were difficult to understand by the farmers. In addition, it lacked representativeness, inconsistency in time of broadcasting and also, lack of awareness on weather information services. Lengthy weather information delivery system was also the other challenge for livestock farmers. This made the information to be too late and less valuable in addressing problems related to climatic risks.

Table 2. Needed agricultural information and their sources for climatic risk adaptation

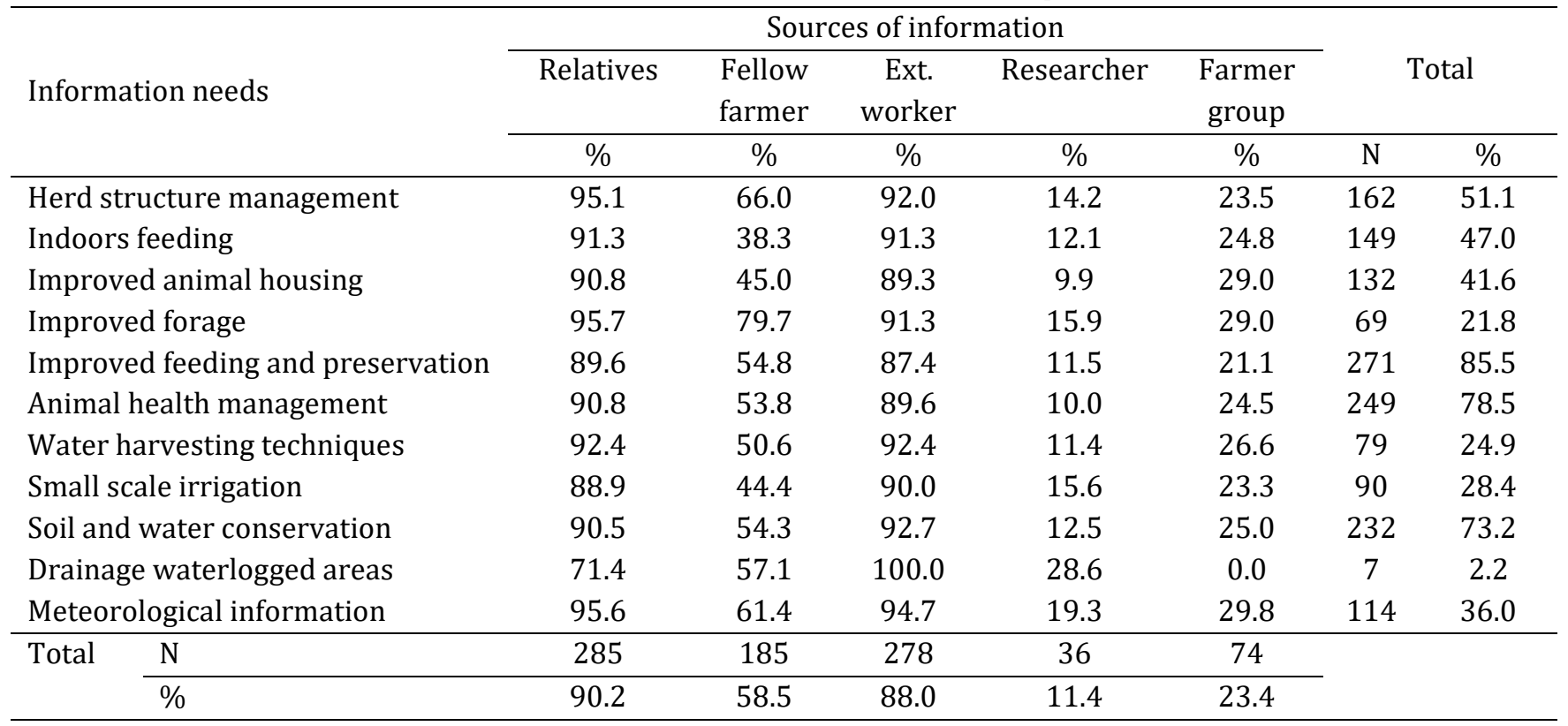

This study also revealed that livestock farmers used different sources to access agricultural information for their climatic risk adaptation. Relatives (90.2\%), extension workers $(88.0 \%)$ and fellow farmers $(58.5 \%)$ were the major sources. This implies that multi and local sources are very important to livestock farmers in acquiring agricultural information for their climatic risk adaptation. According to FGD participants, it enabled the farmers to get full set of required information and also, help them for further clarification and confirmation of information obtained from other sources. Mittal \& Mehar (2013) also reported that multiple sources of information make smallholder farmers effective in managing agricultural risks by accessing adequate and complete agricultural information.

Moreover, the study also signifies the importance of considering farmer's intimates as vital source of information. Social intimacy is fundamental in social learning and innovation diffusion (Kibwika, 2006). As indicated above, relatives and extension workers (i.e., DA) were the most intimates to the farmers. This attributed to relatives-based living style of the farmers, widely using of group extension approach and expansion of public extension services in the study area. In addition, a number of NOGs and semi-NOGs have also been involving in providing extension services in rural parts of the study zone.

According to FGD participants, fellow farmers were also considerably important intimate information source to livestock farmers. They had solidarity, similar background and build morale by relying on each other (Mbanda-Obura et al., 2017). This enabled the farmers to meet easily their peers for exchanging ideas and information. It also reduces communication barriers with experts in enquiring and understanding the technical information (Kamarudin et al., 2015). The extension system of Ethiopia was also constrained by multiple challenges to allow farmers actively participate 
in knowledge generation and diffusion process (Gerba, 2018). As the result, farmers preferred to rely on social learning and local networking for interactions and new knowledge acquisition. This finding aligns with report from central zone of Tigray region (Brhane et al., 2017) and central highland of Ethiopia (Beliyu, 2018), where fellow farmers were major source of agricultural information for smallholder farmers.

Surprisingly, sourcing agricultural information from researchers was invisible for livestock farmers in the study area. This attributed to limited mandates of research institutes and universities in Ethiopian agricultural knowledge system. They majorly responsible for knowledge generation to address agricultural problems (Tewodros and Tesfaye, 2018). In knowledge generation, stakeholders' participation was inadequate. This lessened farmers' chance to work closely with researchers and get first-hand information in the process. Information was reached to livestock farming community in wider by extension staffs. In limited scope, however, researchers delivered information directly to the farmers during their on-farm research programs like on-farm trials, participatory technology evaluation, demonstration and pre-scale ups. This result is supported by Tewodros and Tesfaye (2018) who reported researchers performed pre-scaling up to dissemination agricultural information through demonstration trials.

\section{Agricultural information pathways}

Table 3 shows that livestock farmers in North Wollo zone used different pathways to acquire agricultural information on strategies of climatic risk adaptation. Interpersonal (face-to-face) interaction (80.4\%) was the major information pathways. Farmers acquired agricultural information informally from discussion made with relatives, family members, fellow farmers and extension workers at different events and social functions. This was because farmers had less access to modern information technologies, extension services, higher illiteracy and inadequacy of rural-electrification in the study area.

Moreover, farmers also used farm-visit $(76.7 \%)$ as a major information pathway for their climatic risk adaptation. They visited the farm of successful farmers in their village. It helps them to raise their awareness, share practical experiences and confirm new information obtained from others. In addition, they can see concrete examples and easily understand the advantage of new practices/technologies to apply on their own farms (Frédérique. and Sidi., 2013). In central highland of Ethiopia, however, training and demonstration were the major information pathways for the famers(Beliyu, 2018).

In the study zone, trainings $(57.1 \%)$ and villagemeetings $(52.7 \%)$ were considerably important information pathways. Different trainings were given to the farmers by government and non-government organizations. Some of the trainings were used to educate the farmer about improved agricultural technologies. While others were used as entry point to the community by introducing their programs and activities. In addition to training, different villagemeetings were also organized by local administrators and extension officers to convey awareness raising messages to rural community. Information on government policies, strategies, programs and community mobilization was announced through village-meetings.

There were also farmers who gain agricultural information through radio/audio records (45.4\%), cellphone (37.5\%) and demonstration events (18.0\%). $\mathrm{TV} /$ videorecords and printing materials were the least popular information pathways in the study zone. This was due to unaffordability of modern communication technologies to the farmer, less expansion of electricity coverage and higher illiteracy in rural part of the study zone. Most printed extension materials were also too technical to understand by the farmers, inadequately prepared and distributed; and written mostly by nonlocal language. In addition to these, participants in FGD believed that trainings, village-meeting and study-tours were less appropriate information pathways to the farmers in the study area. Their rationales were biased participants selection, less interactions, demand higher resources to participate, deliver unrelated message with program and also, lack practical learning to demonstrate application and results of innovation. Due to large number of participants, they were inconvenient to shy farmers and women to raise idea and question for further inquiry. In addition to interpersonal communication and farm-visit, demonstration was the preferred pathway to acquire new scientific knowledge and practices. According to the participants in FGD, demonstration was often organized at the field of model farmers and FTCs in their village. This enabled the farmers easily participate and observe practically the 
whole procedure of innovations. It was also powerful in educating illiterate farmers because they easily discuss issues with both peers and experts, jointly solve problems, monitor experiments, observe and compare practices in similar contexts to their own.

Table 3. Pathways/channels used for knowledge acquisition in climatic risk adaptation.

\begin{tabular}{lcc}
\hline Types of information pathways & Frequency & Percentage \\
\hline Self-initiated farm visit & 243 & 76.7 \\
Study tour & 48 & 15.1 \\
Interpersonal (Farmer-to-farmer) communication & 255 & 80.4 \\
Village meetings/ farmer conferences & 167 & 52.7 \\
Field day/ demonstration on FTC and/or farmers' field & 57 & 18.0 \\
Trainings & 181 & 57.1 \\
Printing materials & 24 & 7.6 \\
TV/video & 20 & 6.3 \\
Radio/audio & 144 & 45.4 \\
Mobile phone & 119 & 37.5 \\
\hline
\end{tabular}

\section{Factors influencing choice of agricultural} information pathways

As indicated in Table 5, farmer's decision in selecting a particular information pathway was influenced by the characteristics of the household head. As discussed above, 10 different information pathways were used by livestock farmers. Of which, five of them were selected using Principal Components analysis. These are radio, training, local-meeting, farm-visit and demonstration. In addition, multicollinearity was tested using variance inflation factors (VIF) to measure the inflated value of the variance in regression coefficient due to the correlation of independent variables. As indicated in Table 5, VIF value was 1.62. This implies that the model does not have multicollinearity problems since it is less than 5 .

Multivariate Probit (MVP) model was used to determine factors that influence farmers' decision on information pathways selection. The model was tested for its suitability and explanatory power over univariate probit model. The pair-wise correlation coefficient (rho) of the model indicates that the null hypothesis for independence test was rejected, as the likelihood ratio test $\left(\mathrm{chi}^{2}(10)=43.78\right.$; Prob $\left.>\mathrm{chi}^{2}=0.000\right)$ of independence of error terms of the different information pathways equations is significant. This suggests that the possibility of correlation between the choices of information pathways or the use of number of pathways simultaneously for information needs. Thus, using MVP model is a better specification than the five univariate probit models. Significant value of Wald test (Wald Chi ${ }^{2}$
(60) $=357.43$; Prob $>\mathrm{chi}^{2}=0.000$ ) also allow us to reject the null hypothesis for all regression coefficients in each equation are jointly equal to zero. This shows that the independent variables included in the model had a strong power to explain the variations on the dependent variables. Since the correlation coefficients of the model show only the likelihood occurrence of information pathways, marginal effects were calculated to quantify the influence of explanatory variables over the dependent variables.

As indicated in table 4, the result of pair-wise correlation coefficient across the residuals of MVP model shows that there are10 pairs of information pathways selection. Of which, four of them were statistically significant. These coefficients measure the correlation between the pair of information pathways, after controlling the influence of independent variables in the model. The positive sign indicates a complementary association, whereas the negative sign indicates a substitute association between the two information pathways (Mittal and Mehar, 2015). The result indicates that demonstration was a complementary information pathway for village-meeting and farm-visit. Village-meeting was furthermore complemented by training. Most often, village-meeting and farm-visit lacked scientific facts and procedures in conveying extension messages to the farmers in the study area. Village-meetings were organized for awareness raising on a certain agricultural innovation or development programs by gathering any farmer in the PA. It might not be convenient to all farmers to actively participate in raising issues, questions and sharing 
experience for further discussion and clarity. As the result, farmers remained less informed and looked for other forms of pathway to gain additional information. Training and demonstration were the preferred ones. Training helps the farmers to learn theories and principles of agricultural innovation (Ampaire and Rothschild, 2010). While demonstration was used for skill building on agricultural innovation (David and Cofini, 2017). Demonstration and training had a substitute association. This attributed to demanding higher budget to handle both training and establishing demonstration sites. As the result, most organizations in the study area used either of the two pathways but it depends on the nature of the message, number of farmers need to be addressed, farmers' education level; and available resources and infrastructure development. In addition, farmers also less interested to attend both training and demonstration due to shortage of resources (i.e., laboure and time) and similarity of the message from both pathways. The pathways were also organized at different location and time and thus, farmers attended the convenient one.

Table 4. Correlation coefficient of error terms from five selected equations (Radio, training, Village-meeting, Farmvisit and Demonstration)

\begin{tabular}{lccccc}
\hline Parameter & Coefficient & Std error & P-value & 95\% confidence interval \\
\hline$\rho 21$ & -0.053 & 0.161 & 0.741 & -0.354 & 0.257 \\
$\rho 31$ & 0.0875 & 0.131 & 0.505 & -0.170 & 0.334 \\
$\rho 41$ & -0.064 & 0.146 & 0.663 & -0.337 & 0.220 \\
$\rho 51$ & 0.116 & 0.151 & 0.445 & -0.183 & 0.394 \\
$\rho 32$ & 0.447 & 0.101 & 0.000 & 0.229 & 0.622 \\
$\rho 42$ & -0.159 & 0.136 & 0.243 & -0.409 & 0.113 \\
$\rho 52$ & -0.383 & 0.135 & 0.004 & -0.613 & -0.094 \\
$\rho 43$ & -0.138 & 0.125 & 0.270 & -0.371 & 0.111 \\
$\rho 53$ & 0.357 & 0.103 & 0.001 & 0.141 & 0.542 \\
$\rho 54$ & 0.300 & 0.145 & 0.039 & -0.004 & 0.5521 \\
\hline
\end{tabular}

Note: The indexes refer to the equations: $1=$ Radio, $2=$ training, $3=$ village-meetings, $4=$ Farm visit $\& 5=$ demonstration.

\section{Determinants of radio selection}

Livestock size a farmer owned and extension access influenced significantly farmer's decision in selecting radio as information pathways. The influence of former was positive. This implies that as a unity TLU increased the farmer owned livestock, the likelihood of selecting radio would be increased by $36.1 \%$. In rural part of Ethiopia, livestock size owned is often used as indicator of wealth status of individuals in their community (Yirga et al., 2015). Thus, farmers with higher livestock herd size are consider as resourceful and could afford to buy radio. In addition, radio selection was also positively influenced by extension access. The likelihood of selecting radio would be higher by $27.9 \%$ for the farmers who had a better extension access. This was attributing to having a better extension guidance about the possible ways of information diffusion pathways and the time of broadcasting agricultural information via radio.

\section{Determinants of training selection}

Membership in farmer-group significantly and positively influenced farmers' decision in selecting training. The likelihood of using training would be $19.6 \%$ higher for a farmer who involves in farmer-groups. This is attributed to widely use of group extension approach in Ethiopian extension system in order to decentralize extension services and to promote social-networking, knowledge sharing, joint learning (Girma et al., 2010) and also, to engage the farmer in research and extension activities. Being a member of farmer group would have a better chance to get information about the training from the members or their social network. Moreover, training selection was also influenced significantly but negatively by credit access. The negative association suggested that the chance of training selection would be lower by $23.8 \%$ for a farmer who had better access to credit facility. This is attributed to the higher credit demand and lesser extension participation by resource poor farmers in the study area. Amhara Credit and Saving Institution (ACSI) was the prominent rural microfinance provider in the rural part of the study area. However, its higher interest rate (18\%-19\%), small loan size and group lending system did not encourage resource rich 
farmers, who had alternative financial sources. In addition, the focus of ACSI was also poverty reduction in food insecure areas by providing financial services to rural poor and women farmers (Amhara Credit and Saving Institution, 2004). Despite to this, most rural poor in the study area used the loan for non-agricultural activities, like household consumption, social functions, house construction, seed money for petty trads and also, to cove schooling related costs. In some cases, it was also used to send family members to abroad countries for seeking better job. All these hindered the farmer from actively participant in extension packages; and access training and other services. Thus, credit provision by itself is not an end product in agricultural production promotion rather it should be accompanied by relevant training to build farmers' capacity in business planning, farm managing and marketing.

\section{Determinant of village-meeting selection}

Farmers' decision in selecting village meeting was significantly influenced by sex, education, family size, extension access and agroecology zone. The positive associate of sex implies that village-meeting had a higher chance to be used by male headed household. The likelihood of using village-meeting by male headed household would be $17.1 \%$ higher than female headed. This probably associated with cultural barrier, less access to extension services and shortage of labour for women farmers. Culturally, most public activities in rural parts of Ethiopia were attached to men, whereas domestic one left for women. In addition, the extension system did not encourage rural woman to actively participate in public meetings. Extension messages were often directed to men farmers because it was erroneously assumed that message deliver to men farmers would trickle across to women farmers.

Educational status also positively affected farmer's village-meeting selection decision. The likelihood of using village meeting would be $12.5 \%$ higher for the farmers who attend formal education. This is due to the fact that farmers need to be capable to take notes from the discussion for future referring and sharing with their fellows. Besides, there was also a tendency of preferring educated farmers to invite by experts to attend localmeetings. The rational was educated farmers are better in understanding, articulating ideas and sharing experiences to the participants. They are also visional to accept new ideas/technologies and operating successfully on their farms. Education enriches farmers' ability and willing to make effective changes in their management practice (Kamarudin et al., 2015).

Family size had also a positive influence on farmers' village-meeting selection decision. As a unity increased in family size of the household, the probability of using village-meeting as information pathway would be increased by $16.1 \%$. This attributed to having adequate labour force to manage their farm activities. According to Asrat and Simane (2018), family members are an important source of labour for smallholder farmers in Ethiopia. Thus, having higher family size probably enabled the farmer to get a time freedom to attend different meetings. Furthermore, extension access had also a positive influence on farmer's decision in selecting village-meeting. The probabilities of using villagemeeting would be $20.9 \%$ higher for a farmer who had better extension access. In Ethiopia, village-meeting was one of the frequently used extension approaches of awareness raising on new technologies, extension programs and packages. It was also used for engaging the community in appraising agricultural problems and possible solutions; and getting feedbacks. Moreover, village-meeting selection decision was positively influenced by agroecology. This implies that villagemeeting had higher chance to be used by a farmer who live in highland areas. This attributed to sedentary living style and relatively a better infrastructure development in highland areas of the study zone.

\section{Determinants of farm-visit selection}

Farmers' decision to use farm-visit as information pathway was significantly and positively influenced by years of experience in livestock production. As a unit increased year of experience in livestock production, the likelihood of using farm-visit would be increase by $4.8 \%$. Through long experience, farmers realized the importance of learning new ways of doing from other farmers. Usually, such farm-visit was done from their nearby successful farmers. This gave the farmer better chance to easily visit and share practical knowledge, information and experience. It was also important in avoiding risks of using new technologies proven by other farmers. Moreover, farmers also experienced with inconsistence information and many technical faults from different experts. As the result, they used farm-visit as a strategy of confirming information obtained from other sources by looking for practical evidences.

On the other hand, the used of farm-visit was significantly but negatively influenced by herd size the 
farmer owned. As a unit TLU increased the livestock size of a farmer, the likelihood of selecting farmers-visit would be decreased by $41.5 \%$. This indicates that a farmer with higher livestock size would have a lower probability to use farm-visit. In previous discussion, the size of livestock a farmer owned indicated the wealth status of individual. Thus, a farmer with a higher livestock size was rich and afford to use other means of knowledge acquisition. In most case, such farmers were also used as model farmer by extension workers to apply and promote agricultural innovations in their village. This made the farmers to consider themselves as better off and a good source of knowledge to the rest of the community. As the result, they were less interested in farm-visit to learn from others.

Furthermore, the choice of farm-visit as information pathway was influenced significantly and negatively by extension access. The probability of farm-visit selection would be $9.9 \%$ lower for a farmer who had extension access. This implies that a farmer with a better extension service had less interest to use farm-visit. This was due to the fact that extension workers used various communication pathways to educate the farmers. According to the key informants, training, farmerconference, demonstration, poster and manual were commonly used pathways to disseminate extension messages at their village. Besides, mass medias, like regional and national radios/FMs and TVs, were also used to extend extension coverage in a wider.

\section{Determinants of demonstration selection}

The decision of the farmers in selecting demonstration was influenced significantly and positively by sex of the household head. The positive sign implies that a male headed household had a better chance to use demonstration for information acquisition. Its likelihood to be used by male headed household was $8.5 \%$. This attributed to less access to extension services and cultural barriers for women farmers. Demonstration was one of a public gathering educating practices by extension workers. However, women farmers in rural part of the study area were less interested to participate in demonstration events because they were burdened with different home and farm activities; and lacked resources to apply new technologies as per recommended. Culturally, moreover, they were also not encouraged to express freely their enquiry in public. Demonstration selection decision was also positively influenced by educational status of a farmer. The likelihood of demonstration selection would be $11.1 \%$ higher for educated farmers. This attributed to having a better outlook on improved technologies, extension access and able to read and write. Education helps the farmer to be good in understanding, evaluating and giving constructive feedbacks. As the result, they were frequently invited to take part in many on-farm research and technology promotion activities, like demonstration. Farmers' demonstration selection decision was also influenced significantly and positively by land holding size of household. As a unit increased the size of farmland owned, the probability of using demonstration by a farmer would be increased by $21.8 \%$. This is due to the fact that most invited farmers to attend demonstration events were potential farmers to adopt agricultural innovations. Usually, such farmers in Ethiopia were resource rich farmers (Yirga et al., 2015). Thus, such resource rich farmers allocated some parcel of land to try new agricultural technologies because they had a better shock absorbing capacity (Jairo and Korir, 2019). These farmers not only attending but also, they hosted different demonstration events.

Furthermore, demonstration selection decision was significantly and positively influenced by agroecology where a farmer live in. The positive association indicates that a farmer in the highland area had $19.2 \%$ higher probability in using demonstration than farmers in lowland areas. As move from lowland to highland parts of study zone, livestock farmers become more sedentary and rely more on mixed crop-livestock production system.

This enabled extension works to establish different demonstration sites and gather the farmers for the event. On the other hand, livestock farmers in the lowland areas were movable and live in scattered. Traditionally, lowlanders kept large number of livestock and less interested in using new agricultural technologies. Besides, most lowland parts of the study area were less accessible, harsh and lack infrastructure development to organized demonstration sites and educated the farmer by extension workers. 
Table 5. Multivariate probit estimates and marginal effects for simultaneous choices of information pathways in climatic risk adaptation.

\begin{tabular}{|c|c|c|c|c|c|c|c|c|c|c|c|}
\hline \multirow[t]{2}{*}{ Factors } & \multicolumn{2}{|c|}{ Radio } & \multicolumn{2}{|c|}{ Training } & \multicolumn{2}{|c|}{ Village-meeting } & \multicolumn{2}{|c|}{ Farm-visit } & \multicolumn{2}{|c|}{ Demonstration } & \multirow[t]{2}{*}{ Vif } \\
\hline & Coef. & $\mathrm{dy} / \mathrm{dx}$ & Coef. & $\mathrm{dy} / \mathrm{dx}$ & Coef. & $\mathrm{dy} / \mathrm{dx}$ & Coef. & $\mathrm{dy} / \mathrm{dx}$ & Coef. & $\mathrm{dy} / \mathrm{dx}$ & \\
\hline \multicolumn{12}{|c|}{ Demographic } \\
\hline Sex & -0.07 & -0.03 & 0.08 & 0.02 & $0.43^{* *}$ & 0.17 & 0.33 & 0.08 & $0.50 *$ & 0.09 & 1.18 \\
\hline Age & 0.12 & 0.04 & NA & -0.54 & 0.17 & 0.07 & -0.19 & -0.04 & 0.02 & 0.02 & 2.65 \\
\hline Education & NA & 0.84 & 0.06 & 0.03 & $0.33^{* *}$ & 0.13 & -0.03 & -0.01 & $0.49 * *$ & 0.11 & 1.20 \\
\hline Family size & 0.45 & 0.17 & 0.25 & 0.08 & $0.40 *$ & 0.16 & -0.20 & -0.04 & -0.10 & -0.01 & 1.15 \\
\hline Years of experience & -0.03 & -0.01 & -0.01 & 0.01 & -0.03 & -0.01 & $0.24^{*}$ & 0.05 & 0.02 & -0.01 & 2.93 \\
\hline \multicolumn{12}{|l|}{ Socioeconomic } \\
\hline Land size in ha & -0.60 & -0.22 & -0.13 & -0.08 & 0.52 & 0.20 & -0.52 & -0.14 & $0.90^{* *}$ & 0.22 & 1.87 \\
\hline $\begin{array}{l}\text { Non/off-farm } \\
\text { activities }\end{array}$ & -0.16 & -0.06 & -0.02 & -0.00 & 0.21 & 0.09 & 0.34 & 0.08 & 0.16 & 0.04 & 1.18 \\
\hline Livestock size (TLU) & $0.92^{* * *}$ & 0.36 & 0.27 & 0.14 & 0.07 & 0.03 & $-0.82^{* * *}$ & -0.42 & -0.30 & -0.08 & 1.58 \\
\hline \multicolumn{12}{|c|}{ Institutions } \\
\hline $\begin{array}{ll}\text { Farmer } & \text { group } \\
\text { membership } & \end{array}$ & 0.12 & 0.05 & $0.44^{* *}$ & 0.20 & 0.22 & 0.09 & -0.28 & -0.06 & -0.312 & -0.089 & 1.24 \\
\hline Extension access & $0.77^{* *}$ & 0.28 & -0.01 & 0.01 & $0.52^{* *}$ & 0.21 & $-0.56^{*}$ & -0.10 & $0.81^{* *}$ & 0.12 & 1.10 \\
\hline Credit access & 0.28 & 0.10 & $-0.56^{* *}$ & -0.24 & -0.25 & -0.11 & 0.28 & 0.08 & -0.06 & 0.02 & 2.13 \\
\hline \multicolumn{12}{|c|}{ Location } \\
\hline Agroecology & -0.37 & -0.15 & 0.28 & 0.11 & $0.52^{* * *}$ & 0.20 & 0.14 & 0.04 & $0.92 * * *$ & 0.19 & 1.25 \\
\hline Constant & $-3.71^{* * *}$ & & $8.51^{* * *}$ & & $-3.66^{* * *}$ & & $3.68^{* * *}$ & & $-3.46^{* * *}$ & & \\
\hline Mean vif & & & & & & & & & & & 1.62 \\
\hline
\end{tabular}

Wald $\operatorname{chi}^{2}(60)=357.43 ; \quad$ Prob $>$ chi $^{2}=0.000$;

Likelihood ratio test of $\operatorname{rho} 21=\operatorname{rho} 31=\operatorname{rho} 41=\operatorname{rho5} 1=\operatorname{rho} 32=\operatorname{rho} 42=\operatorname{rho} 52=\operatorname{rho} 43=\operatorname{rho} 53=\operatorname{rho54}=0$ :

$\mathrm{Chi}^{2}(10)=43.783$, Prob $>\mathrm{chi}^{2}=0.0000$

Note: where dy/dx is for discrete change of dummy variable from 0 to 1 , NA refer to a dropped variable in respective regression equation to avoid perfect collinearity; ${ }^{*}, * *$, and ${ }^{* * *}$ represent statistical significancy at $10 \%, 5 \%$ and $1 \%$ of level of variance. 


\section{CONCLUSION AND RECOMMENDATIONS}

Smallholder livestock farmers adapt to climatic risks using different agricultural information on feed preservation, feed quality improvement, animal healthcare, soil and water conservation; and somehow, on herd management, indoors feeding and improved animal housing. The information is sourced from relatives, extension workers and fellow farmers. Moreover, information pathway was also viewed as pertinent in acquiring agricultural information for effective adaptation decision. Interpersonal communication (face-to-face), farm-visit, training and village-meeting are importantly used information pathways. Farmer's decision in selecting particular information pathway is affected by combined factors, but they differ from pathway to pathways. Radio is largely used as information pathway by a farmer with resourceful and have better extension access. While training is more likely used by a farmer involved in farmer-groups; but less by a farmer with a better credit access. The usage of village-meeting is high for a farmer who is male, educated; and has larger family size and better extension access. Besides, it is also more likely used by a farmer in highland areas. Results of the study also showed farm-visit is majorly used by experienced farmers. However, it has less chance to be used by a farmer with a better extension access and higher livestock size. Demonstration in the study zone is majorly used by a farmer who is male, educated, resourceful and has better extension access and lives at highland areas. The study also revealed gender discrimination in accessing agricultural information from village-meetings and demonstration. Women farmers are less benefited from village-meeting and demonstration in acquiring agricultural information on advance strategies of climatic risk adaptation.

The following implications were drawn in order for fostering agricultural information diffusion. To be effective in climatic risk adaptation, livestock farmers in Eastern Amhara Regio need to be updated based on their information needs. Since the farmers used convention information pathway, they were not exposed and updated with various strategies to adapt climatic risks. Therefore, efforts should also be done on supporting the farmer to access modern ICT resources, like radio, TV and Internet. In addition, attention should also be given to demonstration/field day to educate farmers scientific knowledge practically. And also, special strategies should also design to address women farmers through demonstration and village-meeting. Farmers should also be benefited from weather broadcasted information by making the massage simple and understandable terminologies, deliver timely, representative to area and reliable. Finally, further research needs to be done to understand farmers' satisfaction in terms of effectiveness of the existing knowledge, reliability of information sources and appropriateness of information pathways in enhancing the adaptive of capacity of livestock farmers.

\section{FUNDING}

This research work was funded fully by DAADRUFORUM.

\section{REFERENCES}

Adio, E. O., Y. Abu, S. K. YUsuf and S. Nansoh. 2016. Use of agricultural information sources and services by farmers for improve productivity in Kwara State. Library Philosophy and Practice(e-journal), 1456.

Amhara Credit and Saving Institution. 2004. Institutional Profile, Current Status and Future Strategy. ACSI (Amhara Credit and Saving Institution), May, pp. $1-23$.

Ampaire, A. and M. F. Rothschild. 2010. Effects of training and facilitation of farmers in Uganda on livestock development. Livestock Research for Rural Development, 22: 1.

Asrat, P. and B. Simane. 2018. Farmers' perception of climate change and adaptation strategies in the Dabus watershed, North-West Ethiopia. Ecological Processes, 7.

Assefa, H., P. Kibwika, F. B. Kyazze, Z. Mekuriaw and F. Kalanzi. 2020. Climatic risk adaptation strategies by smallholder livestock farmers in Eastern Amhara Region, Ethiopia. European Journal of Agriculture and Food Sciences, 2.

Assefa, H., E. Sehai and A. Tegegne. 2011. Agricultural Knowledge Management in Dairy Production Improvement: The Case of Bure Woreda, West Gojjam Zone, Amhara Region. IUP Journal of Agricultural Economics, 8.

Beliyu, L. 2018. Agricultural knowledge, source and information system in central highland of Ethiopia. Journal of Agricultural Extension and Rural Development, 10: 28-34.

Borko, M. P., Mesfin, Y., Bukero, G., \& Girma, T. . 2014. 
Source, Availability and Use of Agricultural Information by Extension Agents in Southern Ethiopia. International Journal of Recent Research in Interdisciplinary Sciences, 1: 14-24.

Central Statistical Agency. 2013. Ethiopian Rural SocioEconomic Survey (ERSS). file://D:/Research/lit review/CSA_sunses_Survey_Report_2013.pdf.

Chand, M., B. P. Upadhyay and R. Maskey. 2012. Biogas: option for mitigating and adaptation of climate change Lap Lambert Academic Publ Germany.

Cornelißen, T. and K. Sonderhof. 2008. Marginal effects in the probit model with a triple dummy variable interaction termDiskussionsbeitrag.

David, S. and F. Cofini. 2017. A decision guide for rural advisory methods FAO.

Donkoh, S. A., S. B. Azumah and J. A. Awuni. 2019. Adoption of improved agricultural technologies among rice farmers in Ghana: a multivariate probit approach. Ghana Journal of Development Studies, 16: 46.

Frédérique., M. and F. Sidi. 2013. Exchange visits: Advice for improving the impact (Issue April).

Gc, A. and J.-H. Yeo. 2019. Perception to Adaptation of Climate Change in Nepal: An Empirical Analysis Using Multivariate Probit Model. Sci, 1: 12.

Gebru, B., M. Yared and N. Gebremichael. 2017. Sources of information and information seeking behavior of smallholder farmers of Tanqa Abergelle Wereda, central zone of Tigray, Ethiopia. Journal of Agricultural Extension and Rural Development, 9: 47-52.

Gerba, L. D. 2018. The Ethiopian Agricultural Extension System and Its Role as a Development Actor.

Girma, A., A. Kirub, C. Anchala and M. Nigussie. 2010. Soft and Business Skills Management for Ethiopian AgricultureMinstry of Agriculture and Rural Development.

Habtemariam, A., G. E. Tegegni and T. Azage. 2015. Agricultural knowledge management: The case of cattle feed quality improvement in Bure district west Gojjam, Ethiopia. Journal of Agricultural Extension and Rural Development, 7: 1-7.

Hilary, R. S., H. Sseguya and P. Kibwika. 2017. Information quality, sharing and usage in farmer organizations: The case of rice value chains in Bugiri and Luwero Districts, Uganda. Cogent Food \& Agriculture, 3: 1350089.

Jairo, M. and E. Korir. 2019. Climate Knowledge,
Adaptation and Intensity of Adaptation Strategies among Farmers in the Slopes of Mount Kenya. Climatol Weather Forecasting, 7.

Kamarudin, H. D., N. E. A. Aziz, M. K. Zaini and N. Z. Z. M. Ariff. 2015. Exploring Knowledge Sharing Practices among Paddy Farmers towards Building a Foundation for Knowledge Creation. International Journal of Social Science and Humanity, 5: 112-15.

Kibwika, P. 2006. Learning to make changeWageningen Academic Publishers.

Lwoga, E. T., C. Stilwell and P. Ngulube. 2011. Access and use of agricultural information and knowledge in Tanzania. Library Review, 60: 383-95.

Masrom, N. R., M. Hazreen and Y. A. a. Sabri. 2018. Determinants for Knowledge Sharing among Paddy Farmers in Malaysia. International Journal of Academic Research in Business and Social Sciences, 8.

Mbanda-Obura, S. A., I. M. Tabu, D. M. Amudavi and R. K. Obura. 2017. Determinants of choice of agricultural information sources and pathways among sorghum farmers in Ndhiwa Sub-County, Western Kenya. International Journal of Agricultural Extension, 5: 39-49.

Mekuyie, M., A. Jordaan and Y. Melka. 2018. Understanding resilience of pastoralists to climate change and variability in the Southern Afar Region, Ethiopia. Climate Risk Management, 20: 64-77.

Mittal, S. and M. Mehar. 2013. Agricultural information networks, information needs and risk management strategies: a survey of farmers in Indo-Gangetic plains of India CIMMYT.

Mittal and Mehar. 2015. Socio-economic Factors Affecting Adoption of Modern Information and Communication Technology by Farmers in India: Analysis Using Multivariate Probit Model. The Journal of Agricultural Education and Extension, 22: 199-212.

Mtega, W. P. and M. Ngoepe. 2018. Strengthening the Flow of Agricultural Knowledge among Agricultural Stakeholders: The Case of Morogoro Region in Tanzania Ontology in Information Science. InTech.

Murage, A., G. A. Obare, J. Chianu, D. M. Amudavi, C. Midega, J. Pickett and Z. R. Khan. 2012. The effectiveness of dissemination pathways on 
adoption of "Push-Pull" technology in Western Kenya. Quarterly Journal of International Agriculture, 51: 51-71.

Muriuki, N., C. Munyua and D. Wanga. 2016. Communication channels in adoption of technology with a focus on the use of Purdue improved crop storage (PICS) among small scale maize farmers in Kenya. Journal of Biology, Agriculture and Healthcare, 6: 8-12.

Mwalukasa, N. 2013. Agricultural information sources used for climate change adaptation in Tanzania. Library Review, 62: 266-92.

Nyasimi, M., M. A. Radeny, P. Kimeli, C. Mungai, G. Sayula and J. Kinyangi. 2016. Uptake and dissemination pathways for climate-smart agriculture technologies and practices in Lushoto, Tanzania.

Oladimeji, T. E., O. Oyinbo, A. A. Hassan and O. Yusuf. 2020. Understanding the Interdependence and Temporal Dynamics of Smallholders' Adoption of Soil Conservation Practices: Evidence from Nigeria. Sustainability, 12: 2736.

Philimon, T., D. Kidanie, T. Endeshaw, K. Ashebir, T. Abebe, G. E. Weldegebrial, S. Workinesh and T. M. Woldegebriel. 2016. Study on cattle management and marketing practices in Afar region. International Journal of Livestock Production, 7: 55-65.

Rees, D., M. Momanyi, J. Wekundah, F. Ndungu, J. Odondi,
A. Oyure, D. Andima, M. Kamau, J. Ndubi and F. Musembi. 2000. Agricultural knowledge and information systems in Kenya: implications for technology dissemination and development Agricultural Research and Extension Network London.

Rogers, E. 1995. Diffusion of Innovations (Fourth Paperback ed.)New York: The Free Press Simon \& Schuster Inc.

Takele, A., A. Abelieneh and B. A. Wondimagegnhu. 2019. Factors affecting farm management adaptation strategies to climate change: The case of western Lake Tana and upper Beles watersheds, North West Ethiopia. Cogent Environmental Science, 5: 1708184

Tewodros, A. and A. Tesfaye. 2018. Agricultural Knowledge and Technology Transfer Systems in the Southern Ethiopia. African Journal of Agricultural Research, 13: 682-90.

Tiruneh, S. and F. Tegene. 2018. Impacts of climate change on Livestock production and productivity and different adaptation strategies in Ethiopia. Journal of Applied and Advanced Research, 3: 52.

Yirga, C., Y. Atnafe and A. AwHassan. 2015. A multivariate analysis of factors affecting adoption of improved varieties of multiple crops: A case study from Ethiopian highlands. Ethiopian Journal of Agricultural Sciences, 25: 29-45.

Publisher's note: EScience Press remains neutral with regard to jurisdictional claims in published maps and institutional affiliations.

Open Access This article is licensed under a Creative Commons Attribution 4.0 International License, which permits use, sharing, adaptation, distribution and reproduction in any medium or format, as long as you give appropriate credit to the original author(s) and the source, provide a link to the Creative Commons license and indicate if changes were made. The images or other third-party material in this article are included in the article's Creative Commons license, unless indicated otherwise in a credit line to the material. If material is not included in the article's Creative Commons license and your intended use is not permitted by statutory regulation or exceeds the permitted use, you will need to obtain permission directly from the copyright holder. To view a copy of this license, visit http://creativecommons.org/licenses/by/4.0/. 